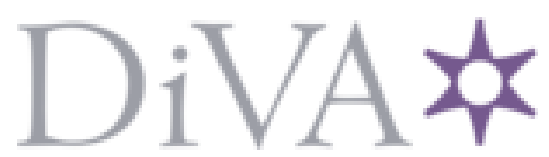

http://www.diva-portal.org

This is the published version of a paper published in Journal of Integrative Environmental Sciences.

Citation for the original published paper (version of record):

Lidskog, R., Sundqvist, G., Kall, A., Sandin, P., Larsson, S. (2013)

Intensive forestry in Sweden: Stakeholders' evaluation of benefits and risk.

Journal of Integrative Environmental Sciences, 10(4)

http://dx.doi.org/10.1080/1943815X.2013.841261

Access to the published version may require subscription.

N.B. When citing this work, cite the original published paper.

Permanent link to this version:

http://urn.kb.se/resolve?urn=urn:nbn:se:oru:diva-32155 
This article was downloaded by: [University of Orebro]

On: 24 October 2013, At: 06:51

Publisher: Taylor \& Francis

Informa Ltd Registered in England and Wales Registered Number: 1072954 Registered

office: Mortimer House, 37-41 Mortimer Street, London W1T 3J H, UK

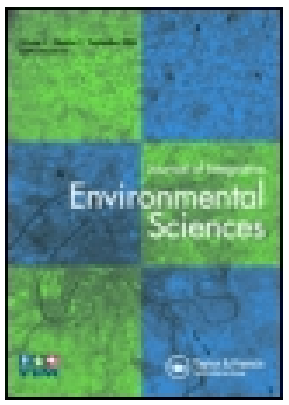

\section{J ournal of Integrative Environmental Sciences}

Publication details, including instructions for authors and subscription information:

http:// www.tandfonline.com/loi/ nens20

\section{Intensive forestry in Sweden: stakeholders' evaluation of benefits and risk}

Rolf Lidskog ${ }^{a}$, Göran Sundqvist ${ }^{b}$, Ann-Sofie Kall ${ }^{b}$, Per Sandin $^{c} \&$ Stig Larsson $^{d}$

a Centre for Urban and Regional Studies, Örebro University, Örebro, SE-70182, Sweden

${ }^{b}$ Centre for Technology, Innovation and Culture, Oslo University, Oslo, 0316, Norway

' Department of Crop Production Ecology, Swedish University of Agricultural Sciences, Uppsala, SE-75007, Sweden

${ }^{d}$ Department of Ecology, Swedish University of Agricultural Sciences, Uppsala, SE-75007, Sweden

Published online: 23 Oct 2013.

To cite this article: Rolf Lidskog, Göran Sundqvist, Ann-Sofie Kall, Per Sandin \& Stig Larsson, J ournal of Integrative Environmental Sciences (2013): Intensive forestry in Sweden: stakeholders' evaluation of benefits and risk, J ournal of Integrative Environmental Sciences, DOI: 10. 1080/ 1943815X. 2013.841261

To link to this article: http:// dx.doi.org/ 10.1080/ 1943815X.2013.841261

\section{PLEASE SCROLL DOWN FOR ARTICLE}

Taylor \& Francis makes every effort to ensure the accuracy of all the information (the "Content") contained in the publications on our platform. Taylor \& Francis, our agents, and our licensors make no representations or warranties whatsoever as to the accuracy, completeness, or suitability for any purpose of the Content. Versions of published Taylor \& Francis and Routledge Open articles and Taylor \& Francis and Routledge Open Select articles posted to institutional or subject repositories or any other third-party website are without warranty from Taylor \& Francis of any kind, either expressed or implied, including, but not limited to, warranties of merchantability, fitness for a particular purpose, or non-infringement. Any opinions and views expressed in this article are the opinions and views of the authors, and are not the views of or endorsed by Taylor \& Francis. The accuracy of the Content should not be relied upon and should be 
independently verified with primary sources of information. Taylor \& Francis shall not be liable for any losses, actions, claims, proceedings, demands, costs, expenses, damages, and other liabilities whatsoever or howsoever caused arising directly or indirectly in connection with, in relation to or arising out of the use of the Content.

This article may be used for research, teaching, and private study purposes. Any substantial or systematic reproduction, redistribution, reselling, loan, sub-licensing, systematic supply, or distribution in any form to anyone is expressly forbidden. Terms \& Conditions of access and use can be found at http://www.tandfonline.com/page/termsand-conditions

Taylor \& Francis and Routledge Open articles are normally published under a Creative Commons Attribution License http://creativecommons.org/licenses/by/3.0/. However, authors may opt to publish under a Creative Commons Attribution-Non-Commercial License http://creativecommons.org/licenses/by-nc/3.0/ Taylor \& Francis and Routledge Open Select articles are currently published under a license to publish, which is based upon the Creative Commons Attribution-Non-Commercial No-Derivatives License, but allows for text and data mining of work. Authors also have the option of publishing an Open Select article under the Creative Commons Attribution License http:// creativecommons.org/licenses/by/3.0/.

It is essential that you check the license status of any given Open and Open Select article to confirm conditions of access and use. 


\title{
Intensive forestry in Sweden: stakeholders' evaluation of benefits and risk
}

\author{
Rolf Lidskog ${ }^{\mathrm{a} *}$, Göran Sundqvist ${ }^{\mathrm{b}}$, Ann-Sofie Kall ${ }^{\mathrm{b}}$, Per Sandin ${ }^{\mathrm{c}}$ and Stig Larsson ${ }^{\mathrm{d}}$ \\ ${ }^{a}$ Centre for Urban and Regional Studies, Örebro University, Örebro SE-70182, Sweden; ${ }^{b}$ Centre for \\ Technology, Innovation and Culture, Oslo University, Oslo 0316, Norway; ${ }^{c}$ Department of Crop \\ Production Ecology, Swedish University of Agricultural Sciences, Uppsala SE-75007, Sweden; \\ ${ }^{d}$ Department of Ecology, Swedish University of Agricultural Sciences, Uppsala SE-75007, Sweden
}

(Received 12 March 2013; accepted 2 September 2013)

\begin{abstract}
There is growing consensus about the need to develop sustainable use of forest resources, but no consensus about how to interpret and implement this goal. Political institutions, governmental agencies, forest companies, and environmental organizations have partly different views on what sustainable forestry means and what strategies to use to achieve it. Not least, the climate change issue has put higher and partly new demands on forests, both as providers of biomass and as carbon sinks, which may be in conflict with other services of the forest's ecosystem. This paper analyses how different Swedish stakeholders evaluate the possibilities for intensive forestry, that is, to increase the production of woody biomass through increased use of fertilizers, improved genetic material, the introduction of exotic tree species, and the use of fastgrowing deciduous tree species. The analysis shows that the pros and cons are evaluated differently, with some stakeholders assessing intensive forestry as a radical break from the current goal of sustainable forestry and others viewing it as according with it. It is concluded that this conflict should be understood as concerning not competing knowledge claims, but competing frames - schemes of interpretation through which the complexity of reality is reduced. This means that the solution is not to be found in improved knowledge but in increased awareness that the involved frames are the source of the conflict.
\end{abstract}

Keywords: intensive forestry; framing; Swedish Forestry Model; biodiversity; climate change; adaptive management

\section{Highlights:}

- The study analyses stakeholders' responses to intensive forestry in Sweden.

- The stakeholders ascribe different benefits and risks to intensive forestry.

- Different knowledge claims are raised, but more knowledge will probably not solve the conflict.

- The conflict about intensive forestry concerns competing frames.

\section{Introduction}

Forestry plays a fundamental role in society. It provides important ecosystem services and at the same time it is essential to the livelihoods for many people, not least for the poorest in the world (McDermott et al. 2010, p. 3). There is an alarming loss of biodiversity

*Corresponding author. Email: rolf.lidskog@oru.se 
associated with the degradation of forest habitats (Reid et al. 2005) and at the same time there are growing demands for forest products on the global market. Apart from providing wood, forests offer other important ecosystem services, such as biodiversity, clean water, erosion protection, fish and wildlife, and recreation, all with potentially conflicting interests. Furthermore, the issue of climate change has put additional demands on the forest in terms of both providing biomass and serving as a carbon sink. Thus, there is a need to respond to the growing interest in forest products, but to do so in a sustainable way. Is it possible to intensify forestry - i.e., significantly increase the yields - without hazarding its provision of ecosystem functions?

Overall, there is a growing consensus about the need to develop a sustainable use of forest resources. There is, however, no consensus about how to interpret and implement this goal. Political institutions, governmental agencies, forest companies, and environmental organizations have partly different views on what sustainable forestry means and what strategies can be used to achieve it. This paper investigates a particular case of conflicting demands on forestry, namely, the proposal for developing a more intensive forestry in Sweden.

Under the influence of climate change policy, proposals have been presented to intensify Swedish forestry in order to meet the predicted - and novel - growing demand for woody biomass as a substitute for fossil fuel, but also because the forest is an important carbon sink. Thus, in 2008 the Swedish Government appointed a commission to investigate the possible benefits and environmental consequences of more intensive silvicultural practices, such as increased use of fertilizers, improved genetic material (e.g., spruce seedlings of clonal origin), the introduction of exotic tree species, and the use of fast-growing deciduous tree species such as hybrid aspen. These practices are currently not allowed on a large scale by Swedish legislation.

The commission analysed possibilities for increased wood production and environmental risks with the introduction of intensified forestry, and reported to the Swedish Government in 2009 (MINT 2009). ${ }^{1}$ The MINT report was thereafter sent out for a referral process in which stakeholders submitted comments.

This paper analyses the different standpoints taken by stakeholders in their responses to the MINT report. The aim is to explain the character of the disagreement, in particular the extent to which it is based on conflicting knowledge claims or on diverging beliefs and values. Besides this specific empirical contribution, the paper also contributes knowledge on the more general issue of how frames are used strategically in handling politically controversial political issues. The analysis is conducted in two steps. It starts by investigating the different standpoints and arguments articulated by the stakeholders, including how they used benefits, risks, and uncertainties as strategic arguments in justifying their standpoints. Thereafter, an analysis is made of how these diverging standpoints are parts of broader frames.

Whereas many studies of natural resource management have concerned national and local opposition to proposals for how to use a particular area (e.g., the establishment of a nature reserve, the clear-cutting of a particular area), this case concerns the general use of a natural resource in an entire country. Hence, the analysis focuses on a stakeholder community on a national scale.

This paper comprises six parts, this introduction being the first. The second part describes the political context for the discussion on intensified forestry: the Swedish forestry model as well as the governmental commission system. The third part presents the design of this study: the theoretical approach, method used, and material analysed. The fourth part presents different stakeholders' responses to the commission's proposals for intensive forestry. The fifth part analyses the diverging standpoints, not least regarding what 
risks and uncertainties are stressed by different stakeholders, and how these standpoints are grounded in the stakeholders' ways of framing intensive forestry. The sixth part concludes by discussing how the management of these kinds of conflicts can be improved.

\section{Political context}

\subsection{The Swedish Forestry Model}

The commercial extraction of woody raw material from forests varies among regions. The boreal region, including Canada, the USA, Russia, and the Nordic countries, contributes a significant portion of the world production of wood products (FAO 2011). Sweden is an economically important member of this group. Of Sweden's total land area of 40.8 million ha, 22.5 million ha are covered by productive forests (defined as stands producing more than $1 \mathrm{~m}^{3}$ per ha and year). The great majority of this area is privately owned, either by small forest landowners (currently numbering about 330,000) or by major timber companies. The average national harvest amounts to about 90 million $\mathrm{m}^{3}$, resulting in an export value of forest products of SEK 122 billion (equivalent to about EUR 13 billion) (Swedish Forestry Agency 2012). The forestry sector currently employs almost 100,000 people (about $2 \%$ of the total labour force), a large proportion of whom live in remote areas with few other job opportunities. Thus, forestry-related businesses are very important for the Swedish economy, and there is strong political consensus that forest resources should be used in a way that ensures they will continue to generate wealth for coming generations.

The Swedish Forestry Act is characterized by two main components: (1) the goal of preserving the environment should be given the same importance as the goal of producing woody biomass and (2) the governing principle of forest management should be "freedom with responsibility"; i.e., a set of rules should lay out the principles for forest use, while the Government acts by providing information, advice, and recommendations (Appelstrand 2012). In addition, voluntary standards in the form of certification systems (i.e., Forest Stewardship Council (FSC) and Programme for the Endorsement of Forest Certification (PEFC)) have come to be pivotal for overseeing compliance with the rules, and sometimes even extending them, because they further specify what the certification agencies consider acceptable (Boström and Klintman 2008; Johansson and Lidestav 2011). The Forestry Act and its interpretation by governing actors can together be viewed as constituting the Swedish Forestry Model. ${ }^{2}$

The present Swedish Forestry Model, based on the Forestry Act of 1993, has from the beginning been well received by many actors concerned about non-commercial assets in the forests, as well as by the forestry sector, which envisages the possibility to continue traditional forestry operations while taking environmental values into due consideration. Forest owners also recognized that the "freedom with responsibility" concept was an important step away from central regulation. It is implicit in the Swedish Forestry Model that environmental values, in particular conserving biodiversity, can be recognized and unanimously acknowledged by actors with different perspectives. This has not been an easy task, largely because of the great uncertainty often associated with adopting a particular management option and the long-term risk of extinction of fauna or flora, for example. Because of the nature of the Forestry Act, it is possible to interpret the implications of the Swedish Forestry Model differently depending on one's perspective.

\subsection{The commission system}

The governmental commission system is an important part of the policy architecture in Sweden (Lundberg 2013). The government appoints a commission in order to prepare new 
legislation and new policies. After being constituted and given general directions, the commission works relatively autonomous from the government. When the commission has delivered its final report, the conclusions are circulated for independent consideration (Olsson et al. 2009, p. 169). The government selects a number of organizations - public agencies, interest organizations, private companies, and professional groups - that it considers to have a stake in the proposed policy and invites them to submit written comments. Besides these invited organizations, any organizations or private citizens who consider themselves to be affected by the proposal can submit comments. The submitted comments, together with the final report, form the basis on which the government will draft a bill and introduce it for parliamentary consideration. The final report and submitted comments may also cause the government to refrain from proposing a bill.

The referral process is a unique feature of the Swedish governmental process (Trädgårdh 2007). It aims to improve the quality of a government bill by providing a comprehensive assessment of the proposal including aspects that may have been overlooked by the commission. It also aims to produce more legitimate policy and legislation - partly by allowing stakeholders to be heard and partly by being a tool for finding common denominators around which consensus can be reached and compromises made (Lundqvist 1982). The referral process is also an instrument for the government to inform itself about stakeholders' perspectives and assessments of a proposal, thereby making it possible to prevent or mitigate conflicts by considering potential points of conflict at the stage of drafting the bill. Thus, the referral process is not only a way for stakeholders to influence policy choices, but also a way for government to create space for strategic action in order to introduce a new policy.

\section{Research design}

\subsection{The governmental investigation}

In March 2008, a Swedish Government Bill proposed several investigations of the possibility to increase forest production (Governmental Bill 2007/08, No. 108). An important incentive for these investigations was the trend of growing international demand for woody biomass. In the Bill, the government emphasizes the climate change issue and states that Sweden could make an important international contribution by providing bioenergy to replace fossil fuels. The Bill also states that the goal of balancing production and environmental concerns should be respected, which means that increased production should be achieved without hazarding the environment. The MINT investigation was established with the task to investigate the feasibility of intensive forestry on abandoned agricultural land and land of low value for nature conservation. The MINT investigation was to include an analysis of possible risk factors associated with intensive forestry.

The Swedish University of Agricultural Sciences was commissioned to conduct the investigation. Some 50 researchers in total (representing forestry, natural sciences, social sciences, and the humanities), for seven separate projects, were recruited to analyse potential future consequences (positive and negative) of introducing more intensive forestry. The commission covered the following areas: (1) definitions, availability of forest land, and assessment of consequences; (2) silvicultural methods for increased growth; (3) social-economic analysis; (4) consequences for cultural environment, recreation, the aesthetics of the landscape, and biodiversity; (5) consequences for soil, water, and greenhouse gases; (6) legal analysis of intensive forestry; and (7) intensive forestry from the perspective of the humanities and social sciences. The government requested that possible risk factors should be investigated. The commission published seven interim 
reports and on 15 September 2009 it delivered its final report "Possibilities for Intensive Forestry", which consists of a summary of the results from the seven projects (all of which had published separate reports) and an overall evaluation of the possibilities and problems associated with intensive forestry (MINT 2009).

The term "intensive forestry" is defined by the commission as collectively referring to silvicultural models that result in significantly increased yields but are not practised today because of restrictions in the current regulatory framework. The report finds that intensive forestry on abandoned agricultural land is limited by the availability of land area. However, a significant amount of the total forest area is considered to have "low conservation values" (about 15 million ha), and of this area, forest lands covering 3.5 million ha (15\% of the total area of productive forests) are considered candidates for intensive forestry in the analysis. The Commission concludes, through a series of scenario analyses, that if a set of novel forestry practices are introduced, the annual yield of woody material could potentially increase by 30 million $\mathrm{m}^{3}$ by 2100 , an estimated increase of almost $20 \%$ over traditional forestry methods.

Expected benefits of intensive forestry are:

- increased production of raw materials for energy and forest-industrial use;

- increased storage of carbon in tree biomass; and

- increased provision of wood-based biofuels that can replace fossil fuels.

Potential risks are:

- increased leakage of nitrogen to watercourses, lakes, and oceans;

- relatively large adverse effects on biological diversity (at the forest stand level); and

- negative consequences for recreation (including hunting), reindeer management, preservation of the cultural environment, and the aesthetics of the landscape.

Altogether, the report finds that the effects of intensive forestry on climate issues will be very positive, while the effects on other environmental aspects will be negative. The report also finds that intensive forestry seems to be economically profitable not only for industry but also for society at large (because of better profitability of forest management and improved greenhouse-gas balances). The report also states that it is necessary to take immediate action, because it will take about 30 years for significant effects to become apparent, due to the crop rotation periods.

In its evaluation, the report states that the potential benefits of intensive forestry are greater than the risks, and recommends that it should be allowed under certain circumstances. "Adaptive management" is presented as the framework under which intensive forestry should be implemented. This kind of management is briefly described as a way of managing a natural resource under conditions of high uncertainty and it consists of a systematic, iterative, and learning-based approach including monitoring systems, stakeholder consultations, feedback mechanisms, and knowledge production. The report concludes: "In the proposed investment in intensive forestry, with a well thought-through adaptive management program, unforeseen negative surprises in terms of both environmental effects and production factors will be possible to monitor and, when necessary, remedy or compensate for" (MINT 2009, p. 116). ${ }^{3}$

\subsection{Theoretical approach}

Regulatory objects are rarely stable or autonomous entities just waiting to be governed (Hood et al. 2001). Instead, issues are constructed as regulatory objects through a 
regulatory process. Actors can ascribe certain characteristics to an object, such as being hazardous or harmless, safe or risky, calculable or indeterminate, natural or unnatural, important or unimportant. By holding a particular view of an issue and trying to convince other actors of its accuracy, a regulatory agency hopes to win support for and prevent criticism of the regulatory proposal.

Therefore, it is important to focus on how various actors frame (conceptualize and understand) the regulatory object at stake (Schön and Rein 1994; Fischer 2003; Hajer and Wagenaar 2003). Frames are structures of belief, values, perception, and appreciation through which actors reduce the complexity of an issue in order to support a certain understanding and promote a specific agenda (Schön and Rein 1994, p. 23). Through frames, a multifarious issue or situation is translated into simpler terms, and certain aspects of it are stressed. By reducing the complexity of an issue to foster a specific understanding of what it fundamentally concerns, frames mobilize opinion for certain kinds of action. Hence, regulation consists of a struggle to control, use, and distribute specific frames; if it is successful, these frames will be agreed upon and taken for granted by the involved actors, and no conflicts will occur. Conflicts may arise between actors despite their sharing a frame (Schön and Rein 1994, p. 3). In these cases - labelled policy disagreements - the actors understand a situation in a similar way, and the conflict can therefore be solved by examining the facts of the situation or developing more knowledge about it. In many cases, however, actors support different frames, which constitute the basis for a policy controversy. Such controversies are not possible to solve by appealing to facts because the actors emphasize different facts or interpret the same fact differently. Thus, when investigating stakeholders' evaluations of the proposal for intensive forestry, it is important to examine not only the arguments for and against the proposal, but also whether the involved actors hold different frames and therefore have different understandings of the consequences of the proposal.

It is also important to investigate what risks they attach to the proposal and the extent to which these risks are seen as manageable. The reason for this is that conceptualizing a regulatory object as a risk entails seeing it as governable (Hood et al. 2001; Power 2007; Lidskog et al. 2011). Risk creates space for action, as it makes the future amenable for calculation, deliberation, and decision-making (Wynne 1996). Unintended negative consequences can be managed in terms of risks, with various regulatory measures being developed in order to minimize potential negative consequences of an activity. By developing knowledge, rules, and capacities, actors believe that risks associated with a proposal can be forestalled; activities will be stopped or modified before they can result in major adverse consequences. Thus, due to differing degrees of confidence in the organization's regulatory capacity - its ability to control specific risks - stakeholders may deem intensive forestry risky or harmless.

\subsection{Method and material}

The empirical material analysed consists of the opinion statements that were submitted in the referral process to the MINT report: in total 52 sets of written comments from different stakeholders.

A qualitative content analysis was used to identify standpoints and arguments (Baxter and Eyles 1999; Bryman 2008; Krippendorff and Bock 2009). The analysis attempted to interpret the positions taken by the actors in terms of risk and uncertainty, in particular in the context of climate change mitigation through intensified forestry and how these positions made use of the Swedish Forestry Model to legitimate their standpoints. 
The opinion statements (which are between 1 and 10 pages in length) were read and categorized. The categorization was done in several steps. First the statements were categorized based on the general conclusions they advocate: whether they are positive, negative, or ambivalent towards intensive forestry. Thereafter, each statement within each category was read through in order to find explicit arguments for the standpoint taken (main arguments), but also to determine to what extent and in what way the statement included arguments against its standpoint (counter-arguments to its own standpoint, as well as why these counter-arguments were given less weight). Of particular importance was to find out how the described pros and cons of the proposal were weighted and to what extent the arguments included a discussion of risk and uncertainty concerning the consequences (positive and negative) of intensive forestry.

To sum up, this study analyses how stakeholders evaluate the proposal for intensive forestry, not least in terms of what benefits and risks they associate with the proposal and how they weigh these in their evaluations. A basic assumption is that stakeholders not only consider narrowly defined risks, but also evaluate them in a wider context, including the possibility to handle them. Research questions guiding the analysis are:

- How are benefits, risks, and uncertainties used as strategic arguments in justifying standpoints?

- What role does the Swedish Forestry Model have in arguments for or against intensive forestry?

- How can one explain the diverging standpoints taken by the stakeholders?

\section{Stakeholders' responses to intensive forestry}

The MINT report was sent to 96 organizations. Of these, 49 responded with written opinion statements, 14 replied that they would refrain from submitting an opinion, and 33 did not respond at all. Apart from these invited organizations, two additional organizations and one private citizen exercised their right to submit opinions. In total, 21 of the opinions were generally positive to the report and its proposal for intensive forestry, 16 were generally critical of it, and 15 were ambivalent (see Table 1).

These results show a great span of standpoints, which is not remarkable. Despite the general agreement on the Swedish Forestry Model, there have been ample conflicts concerning how it should be interpreted and practised (Lindkvist et al. 2011; Appelstrand 2012). Not least among the reasons for this is the plethora of stakeholders and conflicting interests in the forestry sector, which results from the multifunctionality of the forest. The Swedish Forestry Act provides a guiding principle for how to weigh the values of its functions (giving equal weight to production and protection), but when taking decisions this general principle needs to be interpreted, and there are diverging interpretations.

As in earlier conflicts, the responses to the MINT report concern how to interpret and balance the goals of environmental protection and production. Earlier conflicts to a large extent pitted forest owners and environmental organizations against each other, and often concerned specific areas with high environmental values. The proposal for intensive forestry differed; it did not concern areas claimed to be in special need of protection (e.g., proposed nature reserves), and it resulted in a new line of conflict between stakeholders. Also, some stakeholders argued that the proposal implied that the Swedish Forestry Model was now being abandoned.

Those in favour of the proposal argue in line with the MINT report. They emphasize that intensive forestry is founded on two main arguments: that it will increase timber 


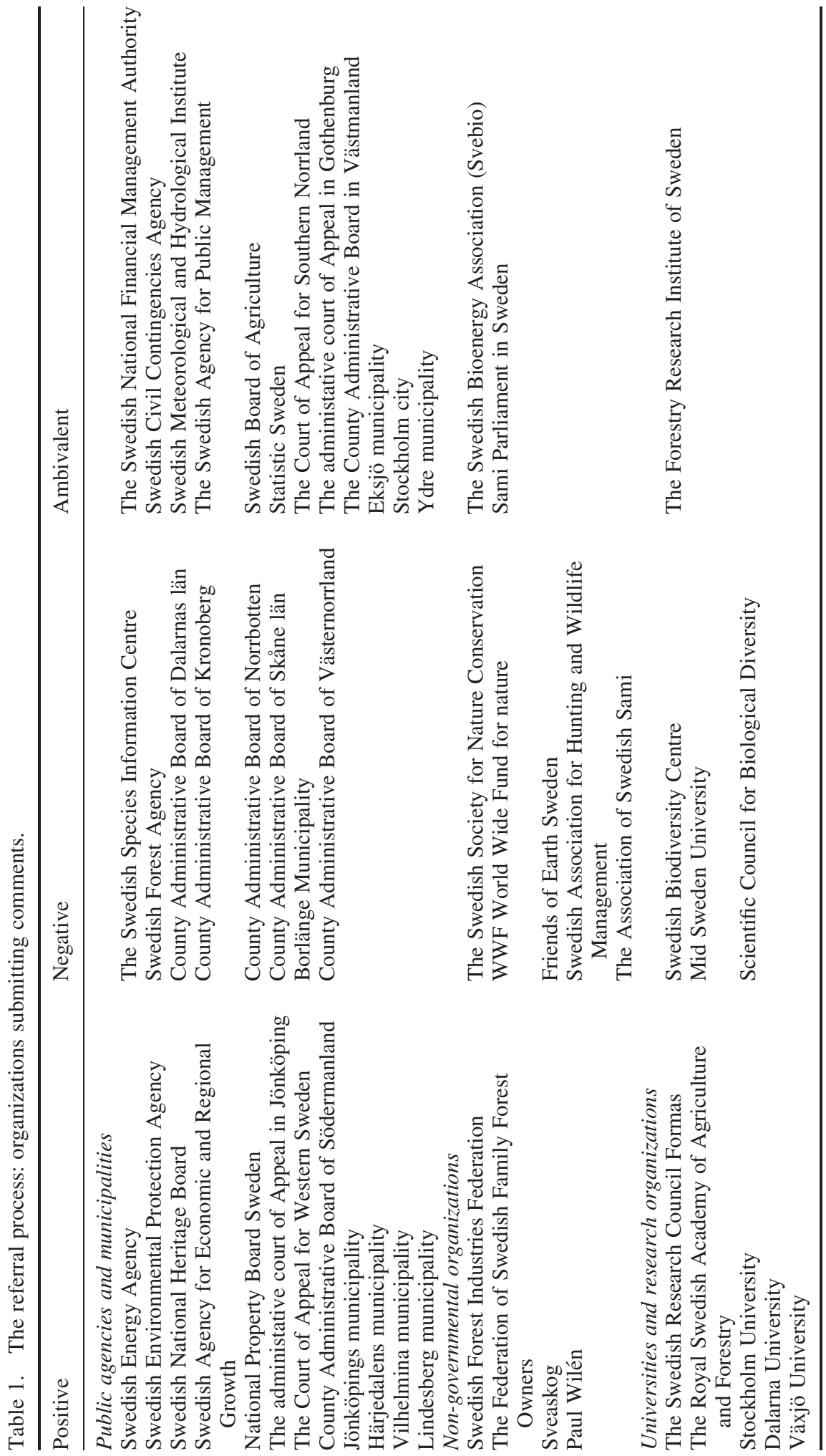


production and that it will reduce greenhouse gases (through increased carbon binding in tree biomass and increased production of biofuels). They also acknowledge that intensive forestry is associated with certain risks, and three in particular: adverse effects on biodiversity, increased contribution to eutrophication, and adverse effects on recreational and cultural environments.

Concerning the balance of assumed benefits and risks, those stakeholders in favour of intensive forestry find the risks to be acceptable. The major reason for this, according to them, is that climate change is such a severe problem that it should be prioritized; the risk and uncertainties will be manageable through adaptive management.

Even if they are in favour of the proposal, some of these stakeholders also highlight a number of deficits in the MINT report. The Swedish Energy Agency stresses that it is unclear what constitutes areas of low value for nature conservation, and forest owners at the Federation of Swedish Farmers argue that there are goal conflicts associated with intensive forestry. Furthermore, some stakeholders - for example, the state-owned forest company Sveaskog - state that the risks are exaggerated, for example, regarding degradation of recreation opportunities, biodiversity, and the aesthetics of the landscape. In addition, some stakeholders emphasize that intensive forestry will be confined to a restricted area and therefore will have rather limited consequences for the recreational use of forests.

Thus, the positive consequences, in terms of reducing anthropogenic climate change, outweigh all the potential negative consequences that are associated with intensive forestry. Also, these potential consequences are seen as manageable through the adaptive management strategy. This is neatly summarized by a forest owner organization in its opinion statement on the MINT report:

One of the Commission's major advantages is that it is broad, clearly stressing both the benefits and risks of intensive cultivation, and makes an overall assessment. This leads to the conclusion that the potential benefits are greater than the risks, which is entirely consistent with our own assessment. This appears reassuring against the background of the wide-ranging strategic environmental impact assessment ... We share the investigation's assessment that the environmental impacts are acceptable as long as the scale of intensive forestry is less than about $10 \%$ of the acreage. (Forest owner at the Federation of Swedish Farmers, our translation)

Those critical of the proposal state that the report has substantial shortcomings, and disagree that it is possible to regulate intensive forestry in a way that will prevent serious negative consequences. A major weakness, according to these organizations, is that intensive forestry has harmful effects on the environment, not least on biodiversity and watercourses (eutrophication caused by nitrogen leakage). Apart from these negative consequences, a number of other environmental risks are mentioned, for example, for the cultural environment, recreation, hunting, and the aesthetics of the landscape. Many of these negative consequences are irreversible, even if they might be possible to compensate. Adaptive management will not be able to handle risks and uncertainties connected with intensive forestry. Many of the stakeholders critical of the proposal view it as a substantially, even dramatically, new direction for Swedish forest policy, a break with the premise of the Swedish Forestry Model that production and protection should be given equal weight.

Thus, even if they acknowledge that intensive forestry will result in increased timber production and reduced effects of greenhouse gas emissions, they argue that the assumed positive climate effects are exaggerated. This means that the negative consequences associated with the proposal are greater than the assumed positive benefits. As two of the submitted opinion statements put it:

Forests and the role of forestry in the climate debate can hardly be considered thoroughly investigated and indisputable. The Swedish Species Information Centre would like to 
emphasize that the aims and measures for managing biodiversity and the climate do not always go hand in hand. Nevertheless, the report draws the conclusion that the baseline scenario could reduce Swedish emissions of carbon dioxide by half. Our conclusion is that the Commission's assessment of the possibility to reduce the greenhouse effect is not reasonable. (The Swedish Species Information Centre, our translation)

If intensive forestry is implemented on a very limited scale and in the right places, the negative consequences, such as for the ecosystem, will probably be negligible. But in that case, on the other hand, the positive effects, such as for the climate, will also be very limited. Against this background, it is difficult to understand the report's conclusion: "The investigation has demonstrated the great potential of intensive forestry." The Swedish Biodiversity Centre interprets the report and its interim reports differently. Our standpoint is that intensive forestry poses risks to biodiversity, both locally and from a regional perspective. The benefits are limited and the consequences of intensive forestry have been inadequately investigated. Therefore, it is not justified at this stage to introduce uncontrolled intensive forestry and thereby abandon the existing forest policy. (Swedish Biodiversity Centre, our translation)

Those ambivalent towards the proposal recognize both benefits and risks of intensive forestry but do not take any firm position. Some of these organizations raise the question whether climate change implies a new balance between the two central goals of production and protection, but do not provide an answer.

\section{Analysis: what is at stake?}

\subsection{Divergent standpoints}

Irrespective of whether they are positive or negative to intensive forestry, the stakeholders share a general understanding that:

- the Swedish forests should be used in a sustainable way;

- the Swedish Forestry Model should be maintained, with equal weight given to the goals of production and environmental protection;

- certain benefits and risks are associated with intensive forestry; the benefits are related to the economic goal of production and to the environmental goal of reducing climate change, while the risks are related to the environmental goals of biodiversity, eutrophication prevention, recreation, and the cultural environment;

- knowledge is of pivotal importance for taking a stand - regardless of whether or not enough knowledge exists today to undertake intensive forestry. With very few exceptions, the statements of opinion referred to knowledge claims in supporting their different standpoints.

However, this shared understanding did not lead to agreement on what actions should be taken. Instead, there are diverging standpoints concerning:

- which forest values are most important;

- the costs and benefits associated with intensive forestry, for instance, how to balance mitigating climate change with other environmental goals, and how these costs and benefits should be measured and estimated;

- to what extent risks and uncertainties associated with intensive forestry are possible to manage through adaptive management;

- whether the proposal implies a break with the Swedish Forestry Model.

Those favouring the proposal for intensive forestry stress: (1) its positive effects in terms of mitigating climate change; (2) that any harmful environmental consequences will be rather contained because intensive forestry would only be permitted on a limited scale 
(15\% of the total area of productive forest) and on areas of little importance for nature conservation; and (3) that a test period of 20 years with adaptive management will make it possible to handle risks that may emerge, or cancel the intensive forestry before any irreversible effect has occurred. Thus, by limiting the issue in time and space, the risks and uncertainties surrounding intensive forestry will be manageable. By stressing that intensive forestry will result in increased production, which will help to reduce the amount of carbon dioxide in the atmosphere, they in effect transcend the previously conflicting goals of production and protection; increasing production becomes a way to protect the environment (by combating climate change).

Those opposing the proposal stress that: (1) the climate benefits are overestimated; (2) the environmental consequences are serious; and (3) adaptive management will not be able to manage the risks associated with intensive forestry. Thus, intensive forestry involves a substantial risk of irreversible adverse effects, and the possible beneficial effects in terms of mitigating climate change are overstated. In this view, intensive forestry will inevitably cause the goal of environmental protection to be subordinated to the goal of production.

In contrast to how the stakeholders argue, we conclude that the disagreements are not primarily about knowledge - about the possibility to know what consequences (positive and negative) intensive forestry will result in - but instead are about frames, about how different environmental goals should be balanced, especially the goals of reducing climate effects and preserving biodiversity. Even if the stakeholders disagree about the scale of positive and negative consequences of intensive forestry, their main divergence does not concern this aspect.

Furthermore, the different standpoints do not solely concern risk analysis, in the sense of measuring probabilities and dangers and calculating the best option. Instead, the discussion revolves around whether it is possible to handle these risks and uncertainties, and to what extent the proposal implies a break with the current policy. Thus, it concerns regulatory capacity: whether or not stakeholders are believed able to handle risks and uncertainties that are not yet fully known.

Thus, the basis of the divergence is that those who are in favour of the proposal and those who are against it apply different frames in order to understand and evaluate intensive forestry. This was, however, never brought to the fore by the stakeholders, either those promoting intensive forestry or those opposing it.

\subsection{Conflicting frames}

Irrespective of whether they were positive or negative to the proposal for intensive forestry, all stakeholders took the Swedish Forestry Model as an unquestioned point of departure in their argumentation. In that sense, the Swedish Forestry Model serves as a master frame, a structuring principle to which all standpoints have to relate (cf. Eder 1996). At the same time, this adherence to the Swedish Forestry Model does not restrict the formulation of different standpoints; it only imposes a need to make explicit that the standpoint is in accordance with the Swedish Forestry Model as opposed to other standpoints.

As stated above, those in favour of and those opposing the proposal embrace different frames, and these guide their understanding of intensive forestry. These frames evaluate the pros and cons of intensive forestry differently, but also weight them differently.

Those positive to intensive forestry frame it primarily in terms of climate change, and their emphasis on forest resources conveys the idea that supporting production also means protecting the environment. Increasing the production of woody biomass becomes an 
environmental goal in itself, and the former tension between the two different goals is here transcended. Negative effects are seen either as possible to handle through adaptive management or as acceptable when balanced against the positive effects of intensive forestry.

Those negative to intensive forestry frame it in a way that does not privilege the climate change issue, but instead considers other environmental goals (such as biodiversity) to have the same weight. Also, they see the positive effects for climate change mitigation as exaggerated. Instead, other (negative) environmental consequences of intensive forestry are emphasized. The tension between production and environmental protection is hence maintained, and it is implied that intensive forestry would give undue weight to the production side when it comes to balancing the two goals.

By judging intensive forestry as congruent with the Swedish Forestry Model, as the proponents do, or as implying a dramatic break with the model, as the opponents do, both sides use the model as a strategic resource in the battle over whether or not intensive forestry should be permitted.

Even if the conflicting views both emphasize the role of knowledge and claim that their reasons for being for or against intensive forestry are a question of knowledge, our analysis finds that this is not the foundation of the conflict. Obviously, different knowledge claims are involved, for instance, the size of the climate effects of intensive forestry (not least its function as a carbon sink) as well as the extent to which it will lead to degradation of recreation opportunities. These kinds of conflicts may, at least in principle, be possible to solve or mitigate with more knowledge (assuming that the organizations see this knowledge as reliable and trustworthy). At the same time, these conflicts play a minor role in the opinion statements; instead, the main argument concerns a more general understanding of what intensive forestry means.

The stakeholders' different arguments are primarily based on how they frame the issue, and questions of knowledge are to a large degree subordinated to the different framings put forward by the involved organizations. Therefore, more detailed knowledge concerning, for example, how much nitrogen leakage will be caused if intensive forestry is implemented, or how much more carbon will be stored in biomass, will hardly change a stakeholder's standpoint. Thus, more knowledge will not lead to general agreement, or at least acceptance, concerning whether intensive forestry should be permitted. The reason for this is that the conflict is not taking place within a shared frame; it is not an example of policy disagreement. If the conflict took place within a shared frame, acquiring more knowledge could be an important means for resolving it (Schön and Rein 1994, p. 3). However, in this case the involved stakeholders have different frames, making the conflict a case of policy controversy. The involved stakeholders evaluate and weigh individual scientific facts differently as well as put forward different consequences of intensive forestry, which means that more and better-disseminated knowledge will probably not be the primary mechanism for resolving the conflict (cf. Wynne 2001).

This is visible not least in the different evaluations of the feasibility of using adaptive management as a way to handle risk and uncertainty. Those in favour of intensive forestry (including the MINT report itself) strongly believe it to be possible to arrange a structure for monitoring, learning, and knowledge production that will prevent more serious environmental harm from occurring ("adaptive management"). They share a confidence in institutions and knowledge, and believe that a specific way to organize the regulation will alleviate adverse effects and prevent irreversible consequences in the future. Those who are opposed to intensive forestry share a belief that more regulation and more knowledge production will not prevent negative consequences from occurring. 
What is at stake in the conflict is not only how to weigh different consequences (not least climate change vs biodiversity) but also how much confidence to have in the regulatory capacity to handle future unintended consequences. There may be also other important things at stake, not least economic considerations related to the importance of increasing the production of woody biomass. The forest sector involves many stakeholders with conflicting interests, and is an area where several different purposes have to collaborate and compromise. Those favouring timber production and bioenergy are more positive towards intensive forestry than those favouring other functions of the forest (e.g., hunting organizations, outdoors associations, and environmental conservation organizations).

Frames determine not only what issues are considered relevant, but also what kinds of knowledge are considered relevant and valid (Hajer and Wagenaar 2003). Accordingly, knowledge claims are put forward as reasons for being positive or negative to the proposal, but this does not imply that better and more detailed knowledge will solve the disagreement. More important is to make explicit and discuss the frames involved in the conflict, as these are what cause stakeholders to interpret intensive forestry differently.

\section{Conclusion}

As shown in our analysis, the responses to the proposal for intensive forestry did not primarily concern risks of intensive forestry in a restricted sense. Instead, it concerned how to understand the broader implications of intensive forestry, how to balance different environmental goals, and whether it will be possible to manage unforeseeable risks. In this process, it was not possible to provide firm and credible answers to the question of what the risks of intensive forestry are.

Instead, the struggle concerned whose claims about risks and benefits should be believed, and to what extent these risks were possible to manage through adaptive management. Thus, governing risk implies not only assessing assumed benefits and risks, but also evaluating the organizational capacity to manage them (cf. Power 2007). A fundamental dividing line between the proponents and opponents of intensive forestry concerned whether it is reasonable to believe that it will be possible to manage risk and uncertainties that are not fully known today but may occur in the future. Different kinds of disturbances - for example, caused by storms, droughts, and insects - are an integral part of forest ecosystems (Andersson and Gong 2010) and since the mid-1970s a large number of studies have been conducted to determine optimal forestry decisions when the management outcome is uncertain (Staupendahl and Möhring 2011). However, the long rotation period, which implies a significant time lag between making decisions and perceiving the consequences (positive and negative), together with uncertainties about climate change, complicates the evaluation of benefits and risks.

Making decisions under conditions of uncertainty always includes both knowledge and values (Lidskog et al. 2011). It concerns not only what we know, but also how much we need to know to be confident that adverse effects will be manageable and not exceed the assumed positive effects. It concerns values not only about how to rank different goals, but also, as stressed above, about how to evaluate the extent to which there will be organizational capacity to handle unforeseeable consequences. Frames describe what things are worth protecting, but also why and how to protect them. In the studied case, the involved organizations shared a general frame (the Swedish Forestry Model). But this master frame did not serve as a platform for developing a shared understanding of the implications of intensive forestry. Instead, there was a conflict between competing frames 
linking intensive forestry with different meanings, and the Swedish Forestry Model is used by the stakeholders as a strategic resource to advance their standpoints and discredit those of others.

However, conflicts between frames are not only something negative. Instead, such situations can be exploited and used in a constructive way (cf. Boström and Klintman 2008). In contrast to many other environmental issues, in which a dominant frame is taken for granted, our case provides an opportunity to make the frames visible, and thereby negotiable, to the involved parties. Obviously, gaining knowledge about the basis of a conflict is not the same as solving it, but if the relevant frames are not analysed, it will be difficult to understand either agreements or disagreement between groups. And other studies have showed that conflicts tend to escalate when actors misinterpret and misunderstand each other's perspectives and actions (Lidskog 2005; Appelstrand 2012).

This conclusion does not provide guidance on how to solve conflicts between different frames. It does, however, stress that greater awareness of the need to include how stakeholders understand and evaluate the issue at stake is an important ingredient in developing socially robust regulation (cf. Callon et al. 2009). Thus, the next step should not be to take decisions based on an evaluation of opinions submitted in the referral process. On the contrary, what is needed is to explicitly and openly discuss and deliberate on the different frames that make intensive forestry a controversial issue. This step has yet to be taken, but hopefully this discussion will result in productive conversations on how to manage Swedish forestry and make it sustainable in the shadow of climate change.

\section{Acknowledgements}

This paper has been written as part of the interdisciplinary programme Future Forest financed by Mistra (The Foundation for Strategic Environmental Research), the Forestry Research Institute of Sweden (Skogforsk), the Swedish University of Agricultural Sciences (SLU), and Umeå University. We wish to thank two anonymous reviewers for their constructive comments on an earlier version of the manuscript.

\section{Notes}

1. MINT is an acronym for the title of the commission's final report: "Möjligheter till intensivodling av skog" (Possibilities for intensive forestry).

2. The Swedish Forestry Model can be seen as a particular variant of the more general model of multifunctionality in forest resource use practised in other parts of the world (Gustafsson et al. 2012). However, the Swedish Forestry Model differs in two important respects (Appelstrand 2007): (1) it is meant to apply to all forest land throughout the country, regardless of ownership, and (2) it assumes that the forest owner actively seeks out and acts on the best available knowledge about trade-offs between exploiting and conserving forest resources.

3. The concept of adaptive management emerged in the mid-1970s, but today - despite its frequent occurrence in scientific articles - it is often used in a vague and ambiguous way (Rist et al. 2012). Although studies and evaluations of adaptive management do exist, there is still a shortage of real-world assessments and applications that include structured decision-making (however, cf. Williams et al. 2009).

\section{References}

Andersson M, Gong P. 2010. Risk preferences, risk perceptions and timber harvest decisions - an empirical study of nonindustrial private forest owners in Northern Sweden. For Policy Econ. $12: 330-339$. 
Appelstrand M. 2007. Miljömålet i skogsbruket: styrning och frivillighet [The environmental goal of Swedish forestry: regulation and voluntariness]. Lund (Sweden): Lund Studies in Sociology of Law No. 26. Swedish.

Appelstrand M. 2012. Developments in Swedish forest policy and administration - from a "policy of restriction" towards a "policy of cooperation". Scand J For Res. 27:186-199.

Baxter J, Eyles J. 1999. The utility of in-depth interviews for studying the meaning of environmental risk. Prof Geogr. 51:307-320.

Boström M, Klintman M. 2008. Eco-standards, product labelling and green consumerism. Basingstoke: Palgrave Macmillan.

Bryman A. 2008. Social research methods. Oxford: Oxford University Press.

Callon M, Barthe Y, Lascoumes P. 2009. Acting in an uncertain world. Cambridge (MA): MIT Press.

Eder K. 1996. The social construction of nature: a sociology of ecological enlightenment. London: Sage.

FAO. 2011. State of the world's forests. Rome: FAO.

Fischer F. 2003. Reframing public policy: discursive politics and deliberative practices. Oxford: Oxford University Press.

Governmental Bill 2007/08, No. 108. En skogspolitik i takt med tiden [A forest policy in line with the times]. Sweden.

Gustafsson L, Baker SC, Bauhus J, Beese WJ, Brodie A, Kouki J, Lindemayer DB, Lohmus A, Pastur GM, Messier C, et al., 2012. Retention forestry to maintain multifunctional forests: a world perspective. BioScience. 62:633-645.

Hajer M, Wagenaar H. 2003. Deliberative policy analysis: understanding governance in the network society. Cambridge: Cambridge University Press.

Hood C, Rothstein H, Baldwin R. 2001. The government of risk: understanding risk regulation regimes. Oxford: Oxford University Press.

Johansson J, Lidestav G. 2011. Can voluntary standards regulate the forestry? Assessing the environmental impacts of forest certification in Sweden. For Policy Econ. 13:191-198.

Krippendorff K, Bock MA, editors. 2009. The content analysis reader. London: Sage.

Lidskog R. 2005. Siting conflicts - democratic perspectives and political implications. J Risk Res. 8:187-207.

Lidskog R, Uggla Y, Soneryd L. 2011. Making transboundary risks governable: reducing complexity, constructing identities and ascribing capabilities. Ambio. 40:111-120.

Lindkvist A, Kardell Ö, Nordlund C. 2010. Intensive forestry as progress or decay? An analysis of the debate about forest fertilization in Sweden 1960-2010. Forests. 2:112-146.

Lundberg E. 2013. Does the government selection process promote or hinder pluralism? Exploring the characteristics of voluntary organizations invited to public consultations. J Civ Soc. 9:58-77.

Lundqvist LJ. 1982. Consultative mechanisms in Sweden's environment protection policy. Environ Int. 7:379-387.

McDermott CL, Cashore B, Kanowski P. 2010. Introduction. In: McDermott CL, Cashore B, Kanowski P, editors. Global environmental forest policies: an international comparison. New York: Earthscan. p. 3-34.

MINT. 2009. Möjligheter till intensivodling av skog. Slutrapport. [Possibilities for intensive forestry. Final report]. Stockholm (Sweden): Governmental Commission 2008, No. 1885. Swedish. Available from: from www.slu.se/mint 09.

Olsson L, Nordfeldt M, Larsson O, Kendall J. 2009. Sweden: when strong third sector historical roots meet EU policy processes. In: Kendall J, editor. Handbook on third sector policy in Europe and organised civil society. Cheltenham: Edward Elgar. p. 159-183.

Power M. 2007. Organized uncertainty: designing a world of risk management. Oxford: Oxford University Press.

Reid WV, Mooney HA, Cropper A, Capistrano D, Carpenter SR, Chopra K, Dasgupta P, Dietz T, Duraiappah AK AK, Hassan R, et al. 2005. Millennium ecosystem assessment synthesis report. Washington (DC): Millennium Assessment and World Resources Institute.

Rist L, Campbell BM, Frost P. 2012. Adaptive management: where are we now? Environ Conserv. 40:5-18.

Schön DA, Rein M. 1994. Frame reflection: toward the resolution of intractable policy controversies. New York: Basic Books. 
Staupendahl K, Möhring B. 2011. Integrating natural risks into silvicultural decision models: a survival function approach. For Policy Econ. 13:496-502.

Swedish Forestry Agency. 2012. Skogsstatistisk årsbok 2012 [Statistical yearbook of forestry 2012]. Jönköping (Sweden): Swedish Forest Agency. Swedish. Available from: www.skogsstyrelsen.se

Trädgårdh L. 2007. Democratic governance in the creation of social capital in Sweden: the discreet charm of governmental commissions. In: Trädgårdh L, editor. State and civil society in Northern Europe: the Swedish model reconsidered. New York: Berghahn Books. p. 254-270.

Williams BK, Szaro RC, Shapiro CD. 2009. Adaptive management: the US department of the interior technical guide. Washington (DC): US Department of the Interior. Available from: http://www.doi.gov/initiatives/AdaptiveManagement/TechGuide.pdf

Wynne B. 1996. May the sheep safely graze? A reflexive view of the expert-lay knowledge divide. In: Lash S, Szerszynsky B, Wynne B, editors. Risk, environment and modernity: towards a new ecology. London: Sage. p. 44-83.

Wynne B. 2001. Creating public alienation: expert cultures of risk and ethics on GMOs. Sci Cult. 10:445-481. 